\title{
Inactivation of proteolytic enzymes by Eubothrium rugosum (Cestoda) from the gut of burbot Lota lota
}

\author{
Galina I. Izvekova, TatyanaV. Frolova and Evgeny I. Izvekov
}

I.D. Papanin Institute for Biology of Inland Waters, Borok, Russian Academy of Sciences, Russia

\begin{abstract}
Parasitic organisms inhabiting the alimentary canal should permanently resist the destructive action of host digestive enzymes. The intestinal parasites were shown to produce specific protease inhibitors protecting them from proteolysis. However, little is known about this adaptive mechanism in cestodes so far, especially for the tapeworms dwelling inside the fish intestines. Here, we explored the ability to inactivate proteolytic enzymes in the fish tapeworm Eubothrium rugosum (Batsch, 1786) (Bothriocephalidea) parasitising the intestine of wild burbot, Lota lota (Linnaeus). The assays were conducted with different concentrations of commercial trypsin and homogenate of intestinal mucosa both being the sources of proteinases. The incubation of live E. rugosum in trypsin solutions of two different concentrations caused a significant decrease in the enzyme activity. The extent of activity reduction was dependent on trypsin concentration. At the same time, the inhibitory effect of the worm incubation medium turned out to be statistically insignificant. These findings suggest partial adsorption of the enzyme to the tegument surface, with its further inactivation. In contrast to the incubation medium, the worm extract suppressed over $80 \%$ of trypsin activity and nearly half of the proteolytic activity in the mucosa homogenate. Notably, the inhibitory activity of the tapeworms hardly depended on their size characteristics. Finally, the research has demonstrated secretion of proteinase inhibitor in E. rugosum, which appears to be essential for its survival in enzymatically hostile environment.
\end{abstract}

Keywords: helminths, fish, digestive enzymes, trypsin, protease inhibitors

Protease inhibitors are important natural regulators of proteolytic activity effectively preventing unwanted hydrolysis of proteins. Hundreds of protein-based protease inhibitors described in ample publications are currently known (for a review, see Rawlings et al. 2004). In multiple forms, they occur in various plant and animal tissues, as well as in some microorganisms. Most of the found and characterised protease inhibitors belong to the group of serine proteases (Molehin et al. 2012).

A crucial feature of helminths' adaptation to their environment is the dual relationship with the host proteases. On the one hand, the parasites use these enzymes to hydrolyse the protein components of food (Izvekova et al. 1997). On the other hand, the tapeworms should constantly resist the destructive action of proteolytic enzymes (Pappas 1987, Soprunov 1987). Helminths have several mechanisms protecting them from host's proteases, including the secretion of inhibitors effectively inactivating these proteases in the environment (Soprunov 1987, Pappas and Uglem 1990, Hawley and Peanasky 1992). In addition, the inhibitors, as well as proteases, may participate in suppression of the host's immune response (Dzik 2006). At present, various subclasses of parasite-derived proteases are identified, their biochemical properties and potential significance for the vital functions and survival of parasites in the host or- ganism are characterised (Zang and Maizels 2001, Knox 2007, Hwang et al. 2009, Kang et al. 2014).

The inhibitors of serine proteases are among the key secretory products of parasites. Being of great importance for the parasite's survival due to their ability to inactivate the host enzymes, they are normally present in the microenvironment and/or secreted by the immune effector cells (Zang and Maizels 2001). These inhibitors regulate protease activity and control a variety of processes related to such activity. Particularly, they play an essential role in protection of a parasite from the host's digestive enzymes and contribute to host-parasite specificity (Morris and Sakanari 1994). Today, the molecular structure of some protease inhibitors is described in nematodes (Grasberger et al. 1994, Zang and Maizels 2001, Jin et al. 2011), trematodes (Hwang et al. 2009, Kang et al. 2014) and some cestodes (Baig et al. 2005, Li et al. 2006).

Unlike the numerous works devoted to protease inhibitors in nematodes and covering quite a wide range of species, similar works on cestodes are scanty and the list of studied species is very short (for a review, see Izvekova and Frolova 2017). Up to now only serine protease inhibitors have been found in cestodes, although it has not always been possible to reveal these inhibitors (Klimenko and Kĕniņa 1971, Dubovskaya 1973). The data on the abil- 
ity of cestodes to suppress the host proteases are particularly scarce for the tapeworms inhabiting the fish intestines (Reichenbach-Klinke and Reichenbach-Klinke 1970, Matskási 1984, Izvekova et al. 2017).

The effect of cestodes of the genus Eubothrium Nybelin, 1922 on their host organisms is actively studied because many species parasitise the intestines of salmonid fishes, such as Atlantic salmon, Salmo salar Linnaeus (Saksvik et al. 2001), rainbow trout, Oncorhynchus mykiss (Walbaum), and sockeye salmon, O. nerka (Walbaum) (Bosi et al. 2005). Infections with species of Eubothrium rarely cause serious pathology in the host fish whose survival is needed for the parasite to complete its life cycle (Mitchell 1993). At the same time, the fish infected with Eubothrium spp. grow slower than uninfected hosts, and this difference eventually increases. Notably, the number of tapeworms poorly correlates with fish weight, suggesting that growth retardation of the salmon may occur even at low-grade infection (Mitchell 1993, Saksvik et al. 2001).

Eubothrium tapeworms parasitise not only salmonids, but also some other fish species, such as the burbot Lota lota (Linnaeus), the only freshwater member of the family Lotidae. The burbot is currently becoming a promising finfish species for cold-water aquaculture. However, in recent years, many burbot populations are threatened, endangered or have disappeared as a result of anthropogenic impact and global warming (Stapanian and Myrick 2015). An additional factor exacerbating these negative effects could be infection with the large cestode Eubothrium rugosum (Batsch, 1786). This species exclusively parasitises the burbots and in some years the prevalence of infection reaches 100\% (Izvekova et al. 2013). Therefore, understanding the adaptation of E. rugosum to the enzymatically hostile intestinal environment is of particular interest. The aim of the present study was to assess the ability of this widespeard cestode to inactivate host proteolytic enzymes.

\section{MATERIALS AND METHODS}

\section{Study object}

The study was conducted on Eubothrium rugosum from the intestine of wild burbot, Lota lota. The tapeworms were obtained from 20 burbots $440-480 \mathrm{~mm}$ long caught in the Rybinsk reservoir (Russian Federation, 58 $\left.22^{\prime} 30^{\prime \prime} \mathrm{N} ; 38^{\circ} 28^{\prime} 04^{\prime \prime} \mathrm{E}\right)$ during the winter period. The number of worms in a single burbot varied from one to ten, and their total weight ranged from $0.31 \mathrm{~g}$ to $1.88 \mathrm{~g}$ per individual fish. The dissection of fish and their intestines, extraction of worms and sample preparation were performed on the ice bath. The fish intestines were dissected, the worms were extracted and thoroughly rinsed in three changes of Ringer's solution $(10 \mathrm{ml}$, $\mathrm{pH}$ 7.5) for cold-blooded animals to remove the host enzymes.

\section{Inactivation of trypsin by the live worms}

In the first series of the experiment, the washed live tapeworms from 15 burbots were divided into sixteen groups of similar weight (from $0.83 \mathrm{~g}$ to $1.39 \mathrm{~g}$ each). Afterwards, eight randomly taken groups of worms were transferred to $5 \mathrm{ml}$ of $0.005 \mathrm{mg} / \mathrm{ml}$ trypsin solution and the remaining eight groups - to $5 \mathrm{ml}$ of $0.01 \mathrm{mg} / \mathrm{ml}$ trypsin solution. Commercial trypsin from porcine pancreas (MP Biomedicals, Santa Ana, California, USA; activity $250 \mathrm{USP}$ ) was used for the experiments. Upon $1 \mathrm{~h}, 2 \mathrm{~h}$ and $24 \mathrm{~h}$ of worms' incubation in trypsin solution at $10^{\circ} \mathrm{C}$, its activity was determined and compared with that of the control trypsin sample kept under the same conditions.

\section{Sample preparation for measuring the inhibitory activity}

In the second series of the experiment, all the tapeworms extracted from the next five burbots and washed as described above were conditionally divided into two size classes: 'short' (eight groups) and 'long' (five groups). The 'short' and 'long' tapeworms were 5-7 cm and 10-20 cm long, respectively. The number of parasites in each group varied from four to ten in the 'short' worms and from one to three in the 'long' ones. Then the worms were transferred to $5 \mathrm{ml}$ of Ringer's solution and incubated for $24 \mathrm{~h}$ at a temperature of $10^{\circ} \mathrm{C}$. The worms remained alive throughout the incubation. After the incubation, the worms were homogenised and the homogenates were diluted with Ringer's solution in the mass-volume ratio of $1: 9$.

In addition, the homogenates were prepared from the intestinal mucosa of the same five burbots for subsequent use as a natural source of proteases. For this purpose, after dissecting the intestine and extracting the worms and the chyme, the mucosa was removed with a plastic spatula, homogenised and diluted with Ringer's solution in the mass-volume ratio of $1: 49$. All homogenates were prepared using glass homogenisers manufactured by Sartorius AG (Göttingen, Germany).

The worm and mucosa homogenates were centrifuged at $6,500 \times g$ for $5 \mathrm{~min}$ at $4{ }^{\circ} \mathrm{C}$. The incubation media resulting from $24 \mathrm{~h}$ keeping the worms in Ringer's solution and contained their excretory/secretory products, extracts obtained by the centrifugation of their homogenates, as well as homogenised mucosa samples were frozen for later use. The protein content in the incubation medium and worm extracts was determined using Lowry's method (Lowry et al. 1951).

\section{Measuring the inhibitor activity}

When measuring the inhibitor activity of worms, the proteinase sources were the homogenate of burbot intestinal mucosa and commercial trypsin. Trypsin was used in concentrations 0.0025 , $0.005,0.0075$ and $0.01 \mathrm{mg} / \mathrm{ml}$ in Tris buffer ( $\mathrm{pH} 7.5$ ). To determine the inhibitor activity, 50-100 $\mu 1$ of worm extract or incubation medium were added to the experimental medium containing $0.5 \mathrm{ml}$ of mucosa homogenate or trypsin solution of a certain concentration, and incubated for $15 \mathrm{~min}$. Simultaneously, the same volume of buffer was added to the respective control sample. After the incubation, the proteolytic activity in the samples was measured.

Besides, the inhibitor activity of E. rugosum samples was compared with that of phenyl-methyl-sulfonyl-fluoride (PMSF), an effective synthetic inhibitor of serine proteases. PMSF was used as a $100 \mathrm{mM}$ solution in dimethyl sulfoxide. For this comparison, $50 \mu \mathrm{l}$ of the PMSF was added to $0.5 \mathrm{ml}$ of trypsin solution.

\section{Measuring the proteolytic activity}

The total activity of alkaline proteases in the homogenate of the burbot intestinal mucosa and the activity of commercial trypsin sample (MP Biomedicals) were determined using 0.3\% (w/v) azocasein in Tris buffer, $\mathrm{pH} 7.5$ as substrate (Alarcón et 
al. 2002). While preparing the control samples, the equivalent volume of buffer solution was added to each sample instead of enzymatically active components. The substrate and enzymatically active sample were incubated for $60 \mathrm{~min}$ at $20-22^{\circ} \mathrm{C}$. The reaction was stopped by adding $1 \mathrm{ml}$ of $0.3 \mathrm{M}$ trichloracetic acid solution. The sediment of non-hydrolysed protein was removed by centrifuging at $6,500 \times g$ for $5 \mathrm{~min}$. The colour development proportional to enzymatic activities was measured in the supernatant at $440 \mathrm{~nm}$ using the Lambda 25 (PerkinElmer, Waltham, USA) spectrophotometer.

The proteinase activity was expressed as the difference of spectrophotometer readings $(\triangle \mathrm{Abs})$ for the sample with substrate versus a blank sample per gram of wet worm, intestinal tissue or trypsin solution for a minute interval $(\Delta \mathrm{Abs} / \mathrm{g} / \mathrm{min})$. Each biochemical assay was conducted in triplicate.

\section{Statistical analyses}

The results are given as means \pm SE. Inhibitory effects were tested using a one-way ANOVA with a post hoc Dunnet's test when comparing multiple means against a single control mean or with the Tukey's test for multiple pairwise comparisons. The level of significant difference was set at $p=0.05$. Statistical analyses were carried out using the software package STATISTICA 6.0 (StatSoft, Inc., Tulsa, Oklahoma, USA).

\section{RESULTS}

\section{Trypsin inhibition by the live worms}

During all the experiments with trypsin, Eubothrium rugosum remained alive and were not hydrolysed. The incubation of the worms in trypsin solution caused a decrease in its activity (Fig. 1). The effect depended on trypsin concentration (Fig. 2). When incubating the worms in $0.005 \mathrm{mg} /$ $\mathrm{ml}$ trypsin solution, their inhibitory action manifested itself only $24 \mathrm{~h}$ later. Meanwhile, at a higher concentration of trypsin $(0.01 \mathrm{mg} / \mathrm{ml})$, the enzyme inhibition became apparent as early as $1 \mathrm{~h}$ later, with a minor further increase in the inhibitory effect after $24 \mathrm{~h}$ incubation (Fig. 1). A drop in trypsin activity at this concentration was significant for all three time intervals tested $(p<0.05)$. After $24 \mathrm{~h}$ incubation, the level of percent inhibition reached approximately $60 \%$ for both trypsin concentrations (Fig. 2).

\section{Weight of worms and protein content in their incubation media and extracts}

In the second series of the experiment, the tapeworms were divided into 'short' and 'long' groups considering the heterogeneity of a natural infrapopulation of E. rugosum in the host fish. The mean weights of the tested samples hardly differed in 'short' and 'long' tapeworms (Table 1, $p>0.05)$. At the same time, the average weight of a single worm was significantly lower in 'short' specimens compared to the 'long' ones ( $p=0.003)$. The protein content in the incubation medium was approximately 22 times lower than in the worm extract for both size groups of parasites. However, no significant difference in protein content was found between the short' and 'long' groups in their incubation medium and extract either (Table 1).

\section{Inhibitory activity of $E$. rugosum incubation medium}

When testing the action of $50 \mu \mathrm{l}$ and $100 \mu \mathrm{l}$ of incubation medium on trypsin activity, no significant inhibitory effect was found from either medium incubated with 'short' or 'long' tapeworms (Fig. 3A). A slight decrease in trypsin activity $(p<0.1)$ was observed only using $100 \mu \mathrm{l}$ of incubation medium from the 'long' tapeworms (at both trypsin concentrations tested).

\section{Inhibitory action of Eubothrium rugosum extract on commercial trypsin sample}

Testing for effect of the worm extract on trypsin activity at $0.005 \mathrm{mg} / \mathrm{ml}$ and $0.01 \mathrm{mg} / \mathrm{ml}$ showed a significant activity decrease in each size group of cestodes when adding $50 \mu 1$ or $100 \mu l$ of the extract $(p<0.05)$ (Fig. 3B). The extract action was not strongly associated with either enzyme concentration, extract volumes tested or tapeworm length. However, it should be noted that in case of the 'short' worms' extract, the percent inhibition of $0.01 \mathrm{mg} / \mathrm{ml}$
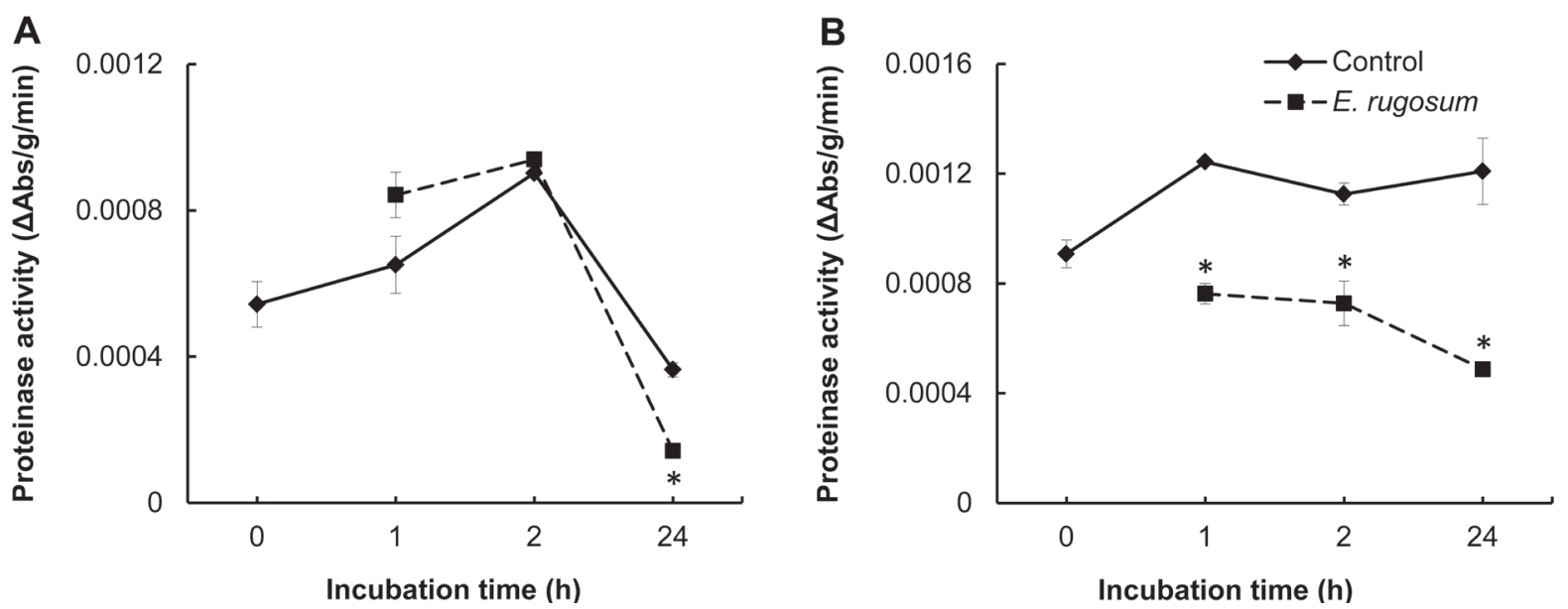

Fig. 1. Effect of live cestodes Eubothrium rugosum (Batsch, 1786) on trypsin activity at concentration of $0.005 \mathrm{mg} / \mathrm{ml}(\mathbf{A})$ and $0.01 \mathrm{mg} / \mathrm{ml}$ (B). 'Control' is the activity of trypsin solution at a given time interval after its preparation. 'E. rugosum' is the activity of trypsin solution after its incubation with the live worms at $10^{\circ} \mathrm{C}$ measured simultaneously with control; $\mathrm{n}=8$. Data represent the mean $\pm \mathrm{SE}\left({ }^{*}\right.$ significant inhibitory effect at a given time point, $\left.p<0.05\right)$. 


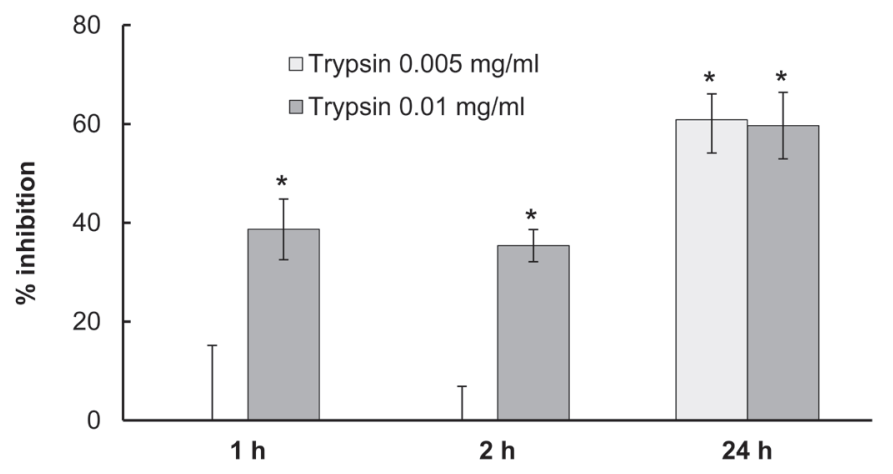

Fig. 2. Percent inhibition of trypsin activity by live Eubothrium rugosum (Batsch, 1786) depending on the incubation period. Inhibitory effects were tested at two different concentrations of trypsin $(0.005 \mathrm{mg} / \mathrm{ml}$ and $0.01 \mathrm{mg} / \mathrm{ml}$; in either case $\mathrm{n}=8)$. Data represent the mean \pm SE (* significant inhibitory effect, $p<0.05)$.

Table 1. Weight of Eubothrium rugosum (Batsch, 1786) and protein content in their incubation media and extracts.

\begin{tabular}{lcccc}
\hline Size class of E. rugosum & \multicolumn{2}{c}{ Mean weight $(\mathrm{g})$} & \multicolumn{2}{c}{ Protein content } \\
\cline { 2 - 5 } & group of worms & single worm & incubation medium $(\mathrm{mg} / \mathrm{ml})$ & extract $(\mathrm{mg} / \mathrm{g})$ \\
\hline 'Short' worms & $0.89 \pm 0.24$ & $0.14 \pm 0.03$ & $0.76 \pm 0.10$ & $17.28 \pm 0.54$ \\
'Long' worms & $1.28 \pm 0.31$ & $1.03 \pm 0.29$ & $0.69 \pm 0.17$ & $15.04 \pm 1.18$ \\
\hline
\end{tabular}
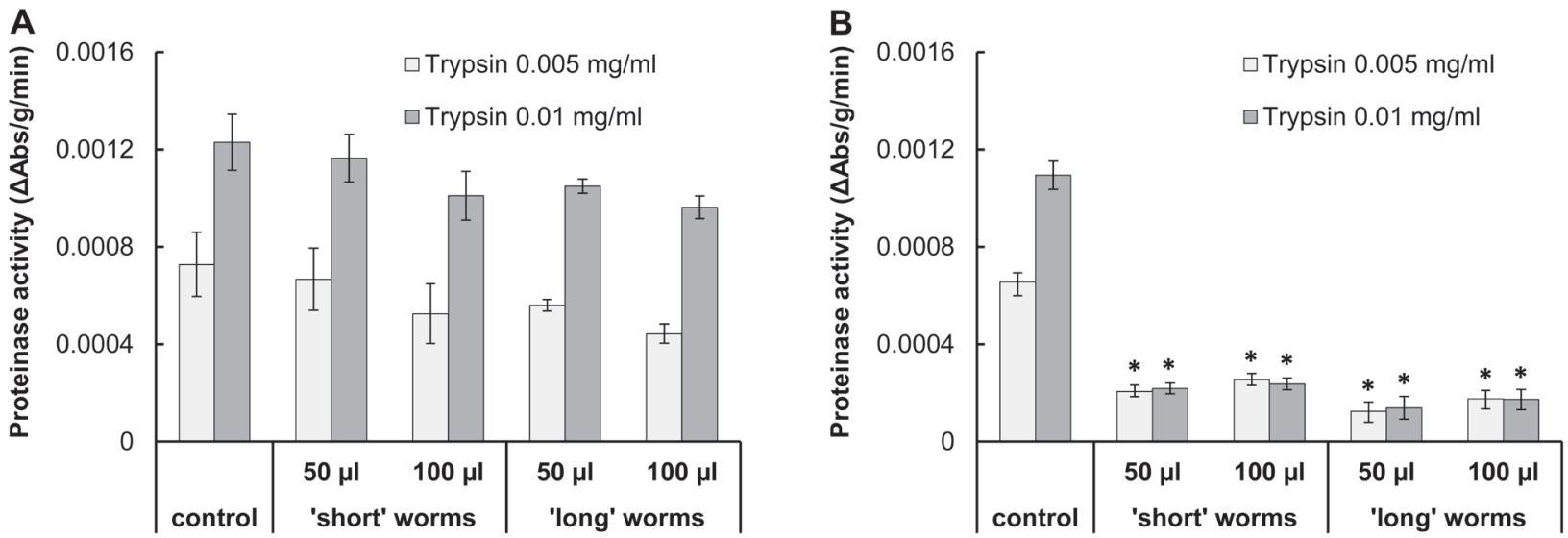

Fig. 3. Changes in trypsin activity when adding different volumes of incubation medium (A) or extract (B) of Eubothrium rugosum (Batsch, 1786). A - the first two bars represent control values, i.e. the activity of $0.005 \mathrm{mg} / \mathrm{ml}$ or $0.01 \mathrm{mg} / \mathrm{ml}$ trypsin solution, respectively. The next bars show the activity of $0.005 \mathrm{mg} / \mathrm{ml}$ or $0.01 \mathrm{mg} / \mathrm{ml}$ trypsin solution when adding $50 \mu 1$ or $100 \mu 1$ of incubation medium obtained from the 'short' worms $(n=8)$ and 'long' worms $(n=5) ; \mathbf{B}$ - the same test conditions and designations as for Part A, only the extract of worms was added instead of incubation medium. Both for A and B, data represent the mean $\pm \mathrm{SE}$ (* significant inhibitory effect, $p<0.05$ ).

trypsin was significantly higher compared to $0.005 \mathrm{mg} / \mathrm{ml}$ solution, $p<0.05$ (Fig. 4).

In control samples, the activity of trypsin gradually rose with its concentration $(\mathrm{F}=29.754, p<0.001)$ (Fig. 5). When adding $50 \mu \mathrm{l}$ of the worm extract, this activity significantly decreased relative to the control values at each trypsin concentration tested. Notably, this reduced level of trypsin activity was rather independent on its initial concentration (Fig. 5). The extracts of worms had a similar effect on trypsin activity regardless of parasite size $(p>0.05)$. When estimating the inhibitory action of cestode extract on trypsin solution depending on its concentration it was shown that at a lower trypsin content of $0.0025 \mathrm{mg} / \mathrm{ml}$ the percent inhibition was about $60 \%$. At a higher concentration of $0.005 \mathrm{mg} / \mathrm{ml}$, the inhibition level reached approximately $80 \%$ displaying no clear changes with further increase in trypsin content (Fig. 6).

\section{Effect of the tapeworm extract on the proteolytic activity of intestinal mucosa}

In this series of experiment (Fig. 7), it was determined that $50 \mu \mathrm{l}$ of the extract obtained both from the 'short' and 'long' worms considerably inhibit the proteolytic activity of intestinal mucosa. This activity was also suppressed by PMSF, an inhibitor of serine proteases. The reported inhibitory effect was statistically significant $(\mathrm{F}=14.8$, $p=0.00002$ ), with each mean significantly differing from control. It was also found that PMSF lowers the proteolytic activity of homogenised mucosa stronger than the extract from the 'short' or 'long' worms does (in both cases, 


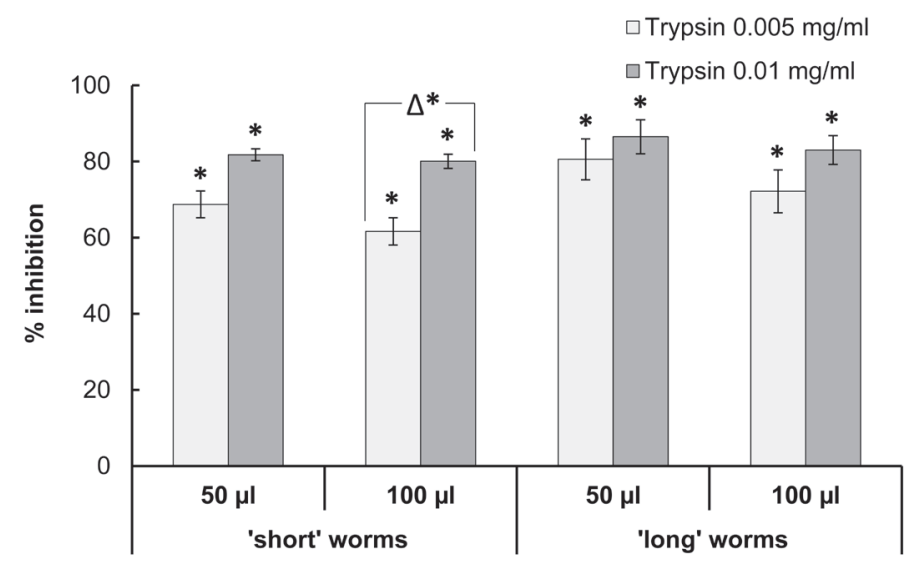

Fig. 4. Percent inhibition of trypsin solution by different volumes of extract from Eubothrium rugosum (Batsch, 1786). Inhibitory effects were tested at two different trypsin concentrations $(0.005 \mathrm{mg} / \mathrm{ml}$ and $0.01 \mathrm{mg} / \mathrm{ml})$ when adding $50 \mu 1$ or $100 \mu 1$ of the extract from the 'short' $(\mathrm{n}=8)$ and 'long' $(\mathrm{n}=5)$ worms. Data represent the mean $\pm \operatorname{SE}\left(*\right.$ significant inhibitory effect; $\Delta^{*}$ significant difference across the two trypsin concentrations tested, $p<0.05)$.

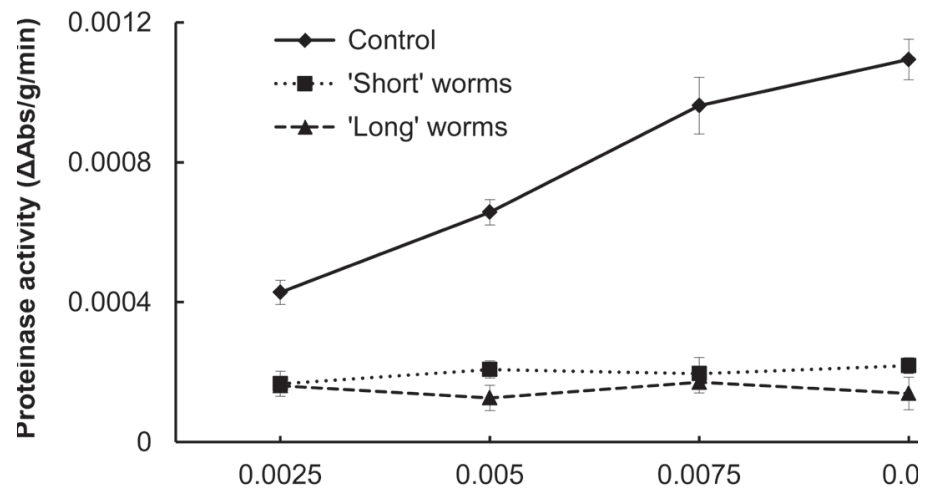

Fig. 5. Effect of the extract from Eubothrium rugosum (Batsch, 1786) on trypsin activity depending on the enzyme concentration. 'Control' is the activity of commercial trypsin at a given concentration. The 'short' worm curve and 'long' worm curve describe the trypsin activity when adding $50 \mu 1$ of the extract obtained from the smaller $(\mathrm{n}=8)$ and larger $(\mathrm{n}=5)$ tapeworms, respectively. Data represent the mean $\pm \mathrm{SE}(*$ significant inhibitory effect, $p<0.05)$.

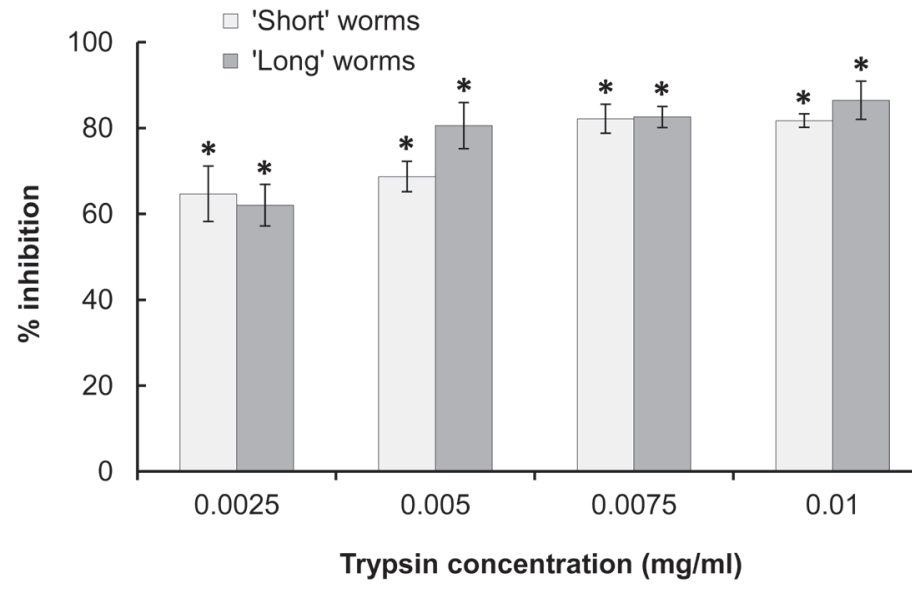

Fig. 6. Percent inhibition of trypsin activity by extract from Eubothrium rugosum (Batsch, 1786) at different enzyme concentrations. The 'short' worm bars and 'long' worm bars characterise the trypsin activity when adding $50 \mu 1$ of the extract obtained from the smaller $(\mathrm{n}=8)$ and larger $(\mathrm{n}=5)$ tapeworms, respectively. Data represent the mean $\pm \mathrm{SE}$ (* significant inhibitory effect, $p<0.05)$.

$p<0.05)$. PMSF inhibited $64 \pm 4 \%$ of mucosal proteolytic activity, while the extract could inhibit only $45 \pm 6 \%$ or
$51 \pm 4 \%$ of the activity (respectively for the 'short' and 'long' worms). 


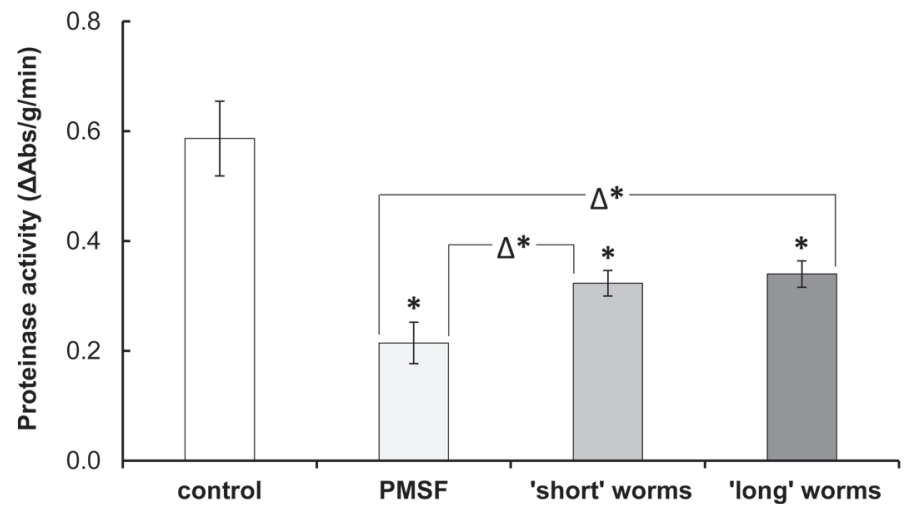

Fig. 7. Effects of extract from Eubothrium rugosum (Batsch, 1786) and phenyl-methyl-sulfonyl-fluoride (PMSF) on proteolytic activity of the intestinal mucosa of burbot, Lota lota (Linnaeus). 'Control' bar is proteolytic activity of homogenate from the burbot intestinal mucosa. 'PMSF' bar is the activity of mucosa homogenate when adding $50 \mu \mathrm{l}$ of PMSF, an inhibitor of serine proteinases. The two last bars display the activity of homogenised mucosa when adding $50 \mu \mathrm{l}$ of 'short' worm extract $(\mathrm{n}=8)$ or 'long' worm extract ( $\mathrm{n}=5)$. Data represent the mean $\pm \mathrm{SE}(*$ significant inhibitory effect; $\Delta *$ significant difference between the inhibitory action of worms extracts and PMSF, $p<0.05)$.

\section{DISCUSSION}

The reported suppression of trypsin activity by the live worms is probably associated with the adsorption of a certain amount of enzyme to the tegument surface with its subsequent inactivation. Trypsin concentration of $0.005 \mathrm{mg} / \mathrm{ml}$ seems to be too low to cause the inhibitory effect after $1 \mathrm{~h}$ incubation. Most likely, a sufficient amount of the enzyme becomes adsorbed upon $24 \mathrm{~h}$, which lowers its activity in the external medium. This could be also confirmed by the rising percent inhibition up to the end of $24 \mathrm{~h}$ incubation of the worms in trypsin solution.

It is also noteworthy that trypsin activity grows with its concentration, while the percent inhibition levels are roughly equal after $24 \mathrm{~h}$ incubation of the live worms at two different enzyme concentrations. Consequently, the absolute amount of inactivated enzyme (proportional to the inhibitor amount) increases with trypsin concentration. This is consistent with the data obtained for the cyclophyllidean cestode Hymenolepis diminuta (Rudolphi, 1819) from the rat intestine. It was shown that during the in vitro incubation of $H$. diminuta with trypsin, $\alpha$ - and $\beta$-chymotrypsin, these enzymes were inactivated on the tegument surface (Pappas and Read 1972a,b). Notably, the inactivation proceeded at the same rate even when the worms were successively transferred to fresh enzyme solution (Pappas and Read 1972b). Since the tapeworms in our experiments stayed alive in trypsin solution, despite the inhibition level being less than $100 \%$, it can be assumed that even the partial inactivation of the major proteolytic enzyme of the intestine, trypsin, ensures the resistance of helminths to their environment.

A lack of clear inhibitory effect of any excretory/secretory products from the worms incubation medium on trypsin activity in our studies correlates with the above hypothesis about the partial adsorption of the enzyme to the tegument surface and its inactivation, at least in part. It is also possible that the amounts of excreted inhibitor were too small to detect them by the method used. The latter hypothesis is supported by a minor decrease in trypsin activity observed when adding $100 \mu \mathrm{l}$ of incubation medium from the 'long' tapeworms to trypsin solutions at both tested concentrations. Similarly, the experiments with $H$. diminuta failed to reveal excretion of active inhibitor into the ambient medium (Pappas and Read 1972b).

However, the inhibition of trypsin by the worm incubation medium was reported for the bothriocephalidean cestode Triaenophorus nodulosus (Pallas, 1781) parasitising the intestine of pike, Esox lucius Linnaeus (see Izvekova et al. 2017), which might be attributed to the release of a protease inhibitor into the medium due to the regular glycocalyx replenishment (Oaks and Lumsden 1971). Possibly, this process in E. rugosum is slower than in T. nodulosus, which would explain the insignificant inhibitory effect in the former species.

The inhibitor activity found in the tapeworm extracts suggests that inactivation of the enzyme occurs after its adsorption to the tegument. It should be stressed that trypsin at both tested concentrations is inhibited incompletely, but to a quite high degree sufficient for protection of the parasite from proteolysis. According to the data on plerocercoids of the diphyllobothriidean cestode Ligula intestinalis (Linnaeus, 1758), the inhibitory activity of the worm homogenate was also higher than that of the cultivation medium (Matskási and Juhász 1977), which also agrees with our results.

Similarly, the attempts to determine the inhibitory capacity of the tegument brush border in H. diminuta (Pappas 1987, Pappas and Uglem 1990) found that the isolated membrane of the tegument in this species is susceptible to the action of proteolytic enzymes. Like the insoluble fraction of the isolated tegument brush border, this membrane does not inhibit bovine trypsin (Pappas 1987). At the same time, the soluble fraction of the isolated $H$. diminuta tegument brush border contains some substances suppressing the proteolytic and amidase activity of bovine trypsin and some proteolytic enzymes of the host's small intestine (Pappas and Uglem 1990). 
The present study on the action of the tapeworm extracts on the activity of trypsin solutions at different concentrations has also shown that the inhibitor produced by the worms does not provide $100 \%$ inactivation of trypsin. When exposed to the tapeworm extract, the activity of trypsin at each tested concentration decreased. Notably, the level of enzyme activity hardly depended on its content, while the percent inhibition grew, which suggests an increase in the absolute amount of inactivated enzyme. Hence, the inhibitory activity of the tapeworm extract is influenced by the trypsin concentration. The inhibition of trypsin solution by the worms' extract was also found in T. nodulosus from the pike intestine (Izvekova et al. 2017).

In the current research, the tapeworm extracts had lower inhibitory effect on the proteolytic activity of the burbot intestinal mucosa than on the commercial trypsin sample. Similar results were obtained in our previous studies on the inhibitory activity of $T$. nodulosus from the pike intestine (Izvekova et al. 2017). This might be due to the fact that the proteolytic activity of the intestinal mucosa includes not only the activity of trypsin, but also chymotrypsin and dipeptidases (Eshel et al. 1993, Natalia et al. 2004). It is also known that serine proteases make the greatest contribution to the total proteolytic activity in different fish species, although this contribution is highly variable (Eshel et al. 1993, Natalia et al. 2004, Kumar et al. 2007). Therefore, in our tests, PMSF as a specific inhibitor of serine proteases could inactivate only $64 \%$ of mucosal proteolytic activity.

On the other hand, Pappas and Uglem (1990) hypothesised that the inhibitor liberated by $H$. diminuta may have a higher affinity and possibly a greater specificity to the proteases operating in the small intestine of its rat hosts compared to bovine trypsin. Our data indicate the opposite, i.e. the inhibitor produced by E. rugosum appears to be more specific to commercial trypsin than to the intestinal proteinases of the burbot. This may be related to different phylogenetic position and levels of enzyme activity in the intestines of their hosts, the burbot and rat, respectively.

According to Pappas (1980), the inactivated enzyme may change the 'microenvironment' of the tapeworm inside the host small intestine, and relatively greater enzyme amounts normally occurring in the small intestine mask the inactivated enzyme. In addition, the portion of trypsin remaining active in the intestine despite the inhibitory action of the worms and operating along with chymotrypsin and dipeptidases apparently ensure some level of the proteolytic activity being sufficient for the vital processes both in the host and parasite.
When dividing E. rugosum into different size classes ('short' and 'long'), the working assumption was that the inhibitory capacity of helminths may depend on their length, and hence the degree of maturity (the latter is expected to be higher in longer specimens). However, this hypothesis had not been confirmed in our experiments, because the inhibitory action of E. rugosum was independent of the worm size. As the average sample weight of the 'short' and 'long' worms hardly differed, it may be assumed that the inhibitory effect is rather determined by the individual weight of the worms than by their maturity level. A clear dependence of trypsin and chymotrypsin inactivation on the tapeworm weight was also shown for H. diminuta by Pappas and Read (1972a,b). These authors attribute this to the glycocalyx replenishment that occurs in $H$. diminuta within six hours as demonstrated by Oaks and Lumsden (1971).

It should be added that in our experiments, not only the inhibitory capacity but also the protein content in the extract and incubation medium were independent of the worm size. This is quite natural, as many protease inhibitors are proteins (Rawlings et al. 2004, Knox 2007). In turn, the presence of protein in the incubation medium of the worms may be explained by the natural renewal of the glycocalyx (Oaks and Lumsden 1971).

In summary, as a result of the present study, it was found that following the incubation of live cestodes E. rugosum in trypsin solutions of different concentrations, the enzyme activity significantly decreased. The degree of activity suppression depended on trypsin concentration. At the same time, the effect of the worms' incubation medium was insignificant suggesting that the inhibitory action of the studied cestodes is probably associated with the adsorption of the enzyme to the tegument surface and its further inactivation. The extract of E. rugosum inhibits more than $80 \%$ of commercial trypsin activity and about $50 \%$ of the proteolytic activity of the homogenised intestinal mucosa of the host fish, burbot. The inhibition of the host proteases is incomplete, but even the partial inactivation of intestinal proteolytic enzymes, including trypsin, makes the helminths resistant to their environment. Future investigations will necessarily focus on the identification and molecular characterisation of the proteinase inhibitors liberated by E. rugosum to clarify their nature and the mechanism of enzyme inactivation.

Acknowledgements. This work was supported by the Russian Foundation for Basic Research (grant number 15-04-02474).

\section{REFERENCES}

Alarcón F.J., Martínez T.F., Barranco P., Cabello T., Díaz M., Moyano F.J. 2002: Digestive proteases during development of larvae of red palm weevil, Rhynchophorus errugineus (Olivier, 1790) (Coleoptera: Curculionidae). Insect Biochem. Mol. Biol. 32: 265-274.

Baig S., Damian R.T., Molinari J.L., Tato P., Morales-Montor J., Welch M., Talhouk J., Hashmeys R., White A.C. JR.: 2005. Purification and characterization of a metacestode cysteine proteinase from Taenia solium involved in the breakdown of human IgG. Parasitology 131: 411-416.

Bosi G., Shinn A.P., Giari L., Simoni E., Pironi F., Dezfuli B.S. 2005: Changes in the neuromodulators of the diffuse endocrine system of the alimentary canal of farmed rainbow trout, Oncorhynchus mykiss (Walbaum), naturally infected with Eubothrium crassum (Cestoda). J. Fish Dis. 28: 703-711.

DubovsKAYA A.YA. 1973: [A study of proteolytic activity in some cestode species.] Parazitologiya 7: 154-159. (In Russian.) 
DzIK J.M. 2006: Molecules released by helminth parasites involved in host colonization. Acta Biochim. Pol. 53: 33-64.

Eshel A., Lindner P., Smirnoff P., Newton S., Harpaz S. 1993: Comparative study of proteolytic enzymes in the digestive tracts of the European sea bass and hybrid striped bass reared in freshwater. Comp. Biochem. Physiol. 106A: 621-634.

Grasbergert B.L., Clore G.M., Gronenborn A.M. 1994: High-resolution structure of Ascaris trypsin inhibitor in solution: direct evidence for a $\mathrm{pH}$-induced conformational transition in the reactive site. Structure 2: 669-678.

Hawley J.H., Peanasky A.J. 1992: Ascaris suum: are trypsin inhibitors involved in species specificity of ascarid nematodes? Exp. Parasitol. 75: 112-118.

Hwang J.H., Lee W.G., Na B.K., Lee H.W., Cho S.H., Kim T.S 2009: Identification and characterization of a serine protease in hibitor of Paragonimus westermani. Parasitol. Res. 104: 495-501.

Izvekova G.I., Frolova T.V. 2017: Proteolytic enzymes and their inhibitors in cestodes. Biol. Bull. Rev. 7: 150-159.

Izvekova G.I., Frolova T.V., Izvekov E.I. 2017: Adsorption and inactivation of proteolytic enzymes by Triaenophorus nodulosus (Cestoda). Helminthologia 54: 3-10.

Izvekova G.I., Kuperman B.I., KuZ'mina V.V. 1997: Digestion and digestive-transport surfaces in cestodes and their fish hosts. Comp. Biochem. Physiol. 118: 1165-1171.

Izvekova G.I., Solovyev M.M., Kashinskaya E.N., Izvekov E.I. 2013: Variations in the activity of digestive enzymes along the intestine of the burbot Lota lota expressed by different methods. Fish. Physiol. Biochem. 39: 1181-1193.

Jin X., Deng L., Li H., Zhang Z., He Q., Yang C., Jiang H., Zhu X.-Q., Peng L. 2011: Identification and characterization of a serine protease inhibitor with two trypsin inhibitor-like domains from the human hookworm Ancylostoma duodenale. Parasitol. Res. 108: 287-295.

Kang J.-M., Ju H.-L., Lee K.H., Kim T.-S., PaK J.H., Sohn W.-M., NA B.-K. 2014: Identification and characterization of the second cysteine protease inhibitor of Clonorchis sinensis (CsStefin-2). Parasitol. Res. 113: 47-58.

KLIMENKo V., Ǩ̌niñ V. 1971: [On the influence of phylogeny and ecology on some biochemical mechanisms of helminth adaptation.] Latvijas Zinatnu Akademijas Vestis. 11: 93-96. (In Russian.)

KNox D.P. 2007: Proteinase inhibitors and helminth parasite infection. Parasite Immunol. 29: 57-71.

Kumar S., Garcia-Carreño F.L., Chakrabarti R., Toro M.A.N., Córdova-Murueta J.H. 2007: Digestive proteases of three carps Catla catla, Labeo rohita and Hypophthalmichthys molitrix: partial characterization and protein hydrolysis efficiency. Aquaculture Nutr. 13: 381-388.

Li A.H., Moon S.-U., Park Y.-K., Na B.-K., Hwang M.-G., OH C.-M., Cho S.-H., Kong Y., Kim T.-S., Chung P.-R. 2006. Identification and characterization of a cathepsin L-like cysteine protease from Taenia solium metacestode. Vet. Parasitol. 141: 251-259.

LOWry O.H., Rosebrough N.J., FARR A.L., RANDALl R.J. 1951: Protein measurement with the Folin phenol reagent. J. Biol. Chem. 193: 265-275.
MatSKÁsi I. 1984: The effect of Bothriocephalus acheilognati infection on the protease and $\alpha$-amylase activity in the gut of carp fry. Symp. Biol. Hung. 23: 119-125.

MatsKási I., Juhász S. 1977: Ligula intestinalis (L., 1758): investigation on plerocercoids and adults for protease and protease inhibitor activities. Parasitol. Hung. 10: 51-60.

Mitchell C.G. 1993: Eubothrium. Aquacult. Inf. Ser. 14: 1-4.

Molehin A.J., Gobert G.N., Mcmanus D.P. 2012: Serine protease inhibitors of parasitic helminthes. Parasitology 139: 681695.

Morris S.R., SAKanari J.A. 1994: Characterization of the serine protease and serine protease inhibitor from the tissue-penetrating nematode Anisakis simplex. J. Biol. Chem. 269: 2765027656.

Natalia Y., Hashim R., Ali A., Chong A. 2004: Characterization of digestive enzymes in a carnivorous ornamental fish, the Asian bony tongue Scleropages formosus (Osteoglossidae). Aquaculture 233: 305-320.

OAKs J., LumSDEN R.D. 1971: Cytochemical studies on the absorptive surfaces of cestodes. V. Incorporation of carbohydrate containing macromolecules into tegument membranes. J. Parasitol. 57: $1256-1268$.

PAPPAS P.W. 1980: Enzyme interactions at the host-parasite interface. In: C.B. Cook, P.W. Pappas and E.D. Rudolph (Eds.), Cellular Interactions in Symbiosis and Parasitism. The Ohio State University Press, Columbus, pp. 145-172.

PAPPAS P.W. 1987: Hymenolepis diminuta: interactions of the isolated brush border membrane with proteolytic enzymes. Exp. Parasitol. 64: 38-47.

PapPas P.W., Read C.P. 1972a: Inactivation of $\alpha$ - and $\beta$-chymotrypsin by intact Hymenolepis diminuta (Cestoda). Biol. Bull. 143: 605-616.

Pappas P.W., Read C.P. 1972b: Trypsin inactivation by intact $H y$ menolepis diminuta. J. Parasitol. 58: 864-871.

Pappas P.W., Uglem G.L. 1990: Hymenolepis diminuta (Cestoda) liberates an inhibitor of proteolytic enzymes during in vitro incubation. Parasitology 101: 455-464.

Rawlings N.D., Tolle D.P., Barrett A.J. 2004: Evolutionary families of peptidase inhibitors. Biochem. J. 378: 705-716.

Reichenbach-Klinke H.-H., Reichenbach-Klinke K-E. 1970: Enzymuntersuchungen an Fischen. II. Trypsin- und $\alpha$-amylase-Inhibitoren. Arch. Fischereiwiss. 21: 72-76.

Saksvik M., Nilsen F., Nylund A., Berland B. 2001: Effect of marine Eubothrium sp. (Cestoda: Pseudophyllidea) on the growth of Atlantic salmon, Salmo salar L. J. Fish Dis. 24: 111119.

Soprunov F.F. 1987: [Molecular Basis of Parasitism.] Moscow, Nauka, 224 pp. (In Russian.)

Stapanian M.A., Myrick C.A. 2015: Ecology, culture, and management of Burbot: an introduction. Hydrobiologia. 757: 1-2.

ZANG X., MaIzels R.M. 2001: Serine proteinase inhibitors from nematodes and the arms race between host and pathogen. Trends Biochem. Sci. 26: 191-197. 